\title{
EL ESTADO SIN ESTADO ENTRE LOS ARAUCANOS/MAPUCHES
}

\author{
Julio Esteban Vezub ${ }^{1}$
}

Tom Dillehay, el arqueólogo y etnógrafo de los kuel, los "montículos vivientes" o estructuras monumentales que representan ancestros, y documentan el sistema de gobierno araucano del tiempo de contacto con los españoles en los bordes del imperio incaico (2011), nos ofrece ahora en este nuevo ensayo una visión de largo plazo acerca de la autonomía araucana/mapuche que enlaza los siglos XVI y XVII con el presente del centro-sur y la Región Metropolitana de Chile en lo que hace a las demandas de autonomía y autodeterminación. Para lograrlo parte de una definición amplia de "soberanía" que ensancha sus límites como relación de poder sobre territorios y poblaciones, cuestionando la noción clásica que la recorta al dominio del Estado moderno. Esta operación conceptual es uno de los aciertos del texto, que está acompañada por la decisión de recoger las categorías que utilizaban los españoles de los siglos tempranos para comprender el fenómeno de la autoridad indígena, como el "Estado indómito", que sería reconocido por la Corona española como un orden político soberano a mediados del siglo XVII, caracterizado por el dominio de señores sobre territorios, siervos y vasallos.

En su conjunto, el ejercicio refuerza la interpretación de las relaciones de poder sin reducirlas a las formas estatales plenas ni al monopolio de la coerción, sugiriendo en cambio que puede haber Estado, "autodeterminación araucana sin gobierno" pero con "gobernanza", incluso ante la falta de aquello que la tradición sociológica reconoce como "atributos de estatidad". Dillehay se separa de los enfoques evolucionistas con que ha sido pensada la emergencia del poder en las sociedades segmentales, y simultáneamente recupera una perspectiva que ha estado en boga entre los araucanistas de diferentes épocas, que asociaron a los mapuches de los siglos XIX y anteriores con los bárbaros del siglo V como lo hizo el explorador chileno Cox (1863), que cruzó los Andes en dirección a las pampas cuando el norte de la Patagonia era un territorio independiente, siendo esta comparación la que encontró pertinente para explicar la estructura política que observó entre la hueste pehuenche.

Esta ampliación del concepto de "soberanía" que propone es congruente con la caracterización de un "imperio" descentrado en los confines del Estado incaico, lo que habilita figurárselo y describirlo analíticamente, como realizó por extenso en su obra anterior al referirse al "sistema de gobierno confederado" (Dillehay 2011:60), o al "Estado premoderno" en este nuevo trabajo. En continuidad con mi comentario precedente, pienso que ello se inscribe en la tendencia saludablemente controversial de la historiografía y la antropología americanas de caracterizar formaciones imperiales allí donde las visiones clásicas han visto la anomia de la barbarie y el nomadismo (aunque no se trate estrictamente de un académico americano véase el trabajo de Pekka Hämäläinen a propósito de los comanches del siglo XVIII). Principalmente, Dillehay encuentra una definición que le permite mostrar que la soberanía no es un fenómeno dado, que se produce históricamente, y que es resultado del habitus. Por otra parte, la detección de un sistema de dominación nómada estuvo entre las intuiciones tempranas sobre los "señoríos ecuestres" de las pampas que realizó Alberto Rex González (1979), el arqueólogo argentino que también estaba motivado por indagar las relaciones e intercambios entre las llanuras y el mundo andino de los incas.

Otro de los méritos del artículo es la síntesis que propone de las principales variables y características del orden político araucano-mapuche, y de las identidades concomitantes del período colonial en el marco de la guerra de Arauco: desarrollo de un sistema defensivo, organización confederal para la guerra, "gobernanza" local y macrorregional, primacía de las redes de parentesco patrilineales y patrilocales, culto a los ancestros, despliegue ceremonial y centralización local del poder político al nivel del lof, el rehue y el ayllarehue,

\footnotetext{
1 Instituto Patagónico de Ciencias Sociales y Humanas, Consejo Nacional de Investigaciones Científicas y Técnicas, Argentina. vezub@cenpat-conicet.gob.ar
} 
acompañamiento de este proceso por un incremento del discurso nacionalista étnico, etc.

Pero en un punto de la lectura me asalta la duda si será posible comprender la soberanía de los grupos étnicos al margen de sus relaciones históricas con el colonialismo, tanto de Antiguo Régimen como nacional republicano. Cierta idealización de la ontología mapuche en ruptura con la española plantea la paradoja de las formas de gobierno indígena que podrían ser vistas más allá de sus vinculaciones con los mecanismos y lógicas de dominación estatal, ya sean impuestas directamente o en el marco de las disputas hegemónicas que los europeos, criollos y nativos establecían a la distancia desde los enclaves fronterizos como Valdivia en el Pacífico, y Carmen de Patagones en el Atlántico. De ser así nos encontraríamos ante el oxímoron de un estado sin Estado, este último en mayúscula para contrastar con el primero su condición de Leviatán, o actor dotado de voluntad en la perspectiva crítica de Abrams (1988). Este contraste resultaría congruente con la apuesta de Dillehay, quien recoge de las fuentes españolas del siglo XVI que "estado" significaba una condición política organizada, “...y no necesariamente el nivel de organización social que reconocemos en la literatura especializada contemporánea" (Dillehay 2011:19).

La búsqueda de alianzas y la tendencia al verticalismo orientaron una parte fundamental de la política y los discursos mapuches, junto con el "deseo de estado" que alimentó las decisiones de muchos jefes indígenas del siglo XIX (Comentario personal Diego Escolar, 2011). Probablemente, este proceso se dio desde los siglos anteriores, como señala Dillehay al recordar que los araucanos constituyen el único grupo étnico que concluyó tratados formales y límites fronterizos con la Corona española, aunque esta excepcionalidad resulte demasiado taxativa si se consideran los pactos que establecieron otros grupos sudamericanos desde el siglo XVI (Levaggi 2000). Esto permite sugerir que la "libre determinación araucana sin estado", pero con "gobierno", no sería completamente ajena a las prácticas de la sujeción y la negociación colonial que se daba en sus márgenes.

Esta dualidad podría pensarse en función de la heteronomía política de los "grandes hombres" mapuches, quienes se percibían a sí mismos como parte de una casta nobiliaria de guerreros que establecía alianzas entre iguales con los españoles (Menard 2010), y en la tendencia a las “...formas difusas, colectivas y centrífugas del poder político mapuche" (Pavez 2008:30). Dillehay advierte estos problemas al señalar que las poblaciones mapuches no presentaron un frente unificado, que las formas del parentesco habrían sido perturbadas por la relación colonial y una serie de instituciones como los parlamentos y los "indios amigos", a lo que deberíamos agregar la mención de las misiones religiosas, el comercio y la distribución de raciones o agasajos, aquello que Boccara reconoció como los "dispositivos disciplinarios" que se desplegaron vigorosamente desde las reformas borbónicas en adelante (1998). Según a mi razonamiento, las perspectivas autonomistas mapuches encontrarían su fundamento en la posición crecientemente subalterna desde la cual eran enunciadas, antes que en un modelo radicalmente distinto de politicidad. $\mathrm{La}$ emergencia del nacionalismo mapuche que destaca Dillehay no haría sino ahondar esta impresión, en tanto identidad específicamente moderna que se desarrolla a la par de las lógicas propias de la soberanía y la legitimidad estado nacionales.

La tesis de Boccara sobre la etnicidad es recogida y a la vez se renueva en esta interpretación de Dillehay, quien reemplaza la categoría de "etnogénesis" por la de "etnomorfosis", sosteniendo que la identidad araucana se habría configurado aun antes de la presencia de los españoles en el sur sudamericano. Encuentro interesante esto último como el retorno a una visión más clásica de la etnicidad, ya no como fenómeno de invención, imposición, ni dispositivo clasificatorio occidental, como sistema de analogía con las naciones europeas, etc., sino como el resultado de la oposición de atributos y prácticas culturales que incluyen la territorialidad, junto con varios indicadores que serían reconocibles mediante el registro arqueológico y etnohistórico. Esta continuidad de elementos preexistentes abona la hipótesis de Menard (2010), quien también discute con Boccara pero en una dirección diferente, cuando plantea que los mapuches del siglo XVIII seguirían siendo reche en virtud del peso de lo local, tanto en las estructuras políticas nodales, dispersas o atomizadas como en lo relativo a la construcción de formas de la identidad que escapan al anclaje nacional.

Es en este punto cuando acudo a la mención del análisis de las redes libres de escala para comprender qué formas de regulación y articulación del lazo social pudieron funcionar en este caso de estado sin Estado, abusando de la interpretación de Dillehay, identificando la morfología de las relaciones de 
poder y las estructuras que los jefes-parientes se daban en torno a la guerra, la producción y la circulación de bienes incluida la fuerza de trabajo, y el ceremonial. Esta metodología recupera la figura del rizoma con que ha sido descrita la formación sociopolítica nómada, dicho esto en un sentido metonímico que incluye agricultores, donde cualquier punto de una estructura es asociable con otro, aunque no sean correlativos dentro de un tejido heterárquico (Deleuze y Guattari 1988:13; Sloterdijk 2006:23). Ello permite reconocer nodos fuertes y redes egocentradas, pero también la conectividad de los lazos débiles que contribuyen a la cohesión de un sistema cuya soberanía está descentrada. Algo similar sucede con la integración virtual de territorios discontinuos, superpuestos y distantes a ambos lados de la cordillera de los Andes por parte de los linajes mapuches (Bello 2010).

Según Dillehay, los mapuches aparecen como un conglomerado de distintos grupos étnicos, aunque también enfatiza los cambios que se produjeron a nivel regional en la definición de macroidentidades como lo ha hecho Boccara (1998). Reconoce la conformación de una unidad cultural extensa, es decir, aquello que Bechis (2008) denominó el "área arauco-pampeana-norpatagónica". Este pensamiento combina el registro de la diversidad histórica con una metafísica de la totalidad mapuche que se reflejaría en la adherencia estricta al admapu, o código de comportamiento ancestral, como una actitud de rechazo a las pautas culturales europeas. Ello redundaría en un "proyecto claro y coherente" de defender su independencia, integridad étnica y sistema de gobierno. A su vez, esta "acción colectiva" estaría en la base de la soberanía mapuche. Aunque descentralizado, el sistema de gobierno se apoyaría en un acuerdo de redes sociopolíticas, supraétnicas y de liderazgos interinstitucionales. Especialmente en lo relativo a la territorialidad, y a la unidad de objetivos, esta visión de la totalidad u homogeneidad es discutida actualmente por los referentes de otros particularismos como los ranqueles y tehuelches, o mejor dicho günuna küne y aónikenk, si se quiere resaltar la proyección norteña y metropolitana que tendría el etnónimo "tehuelche" en mapuzungun para referirse a las poblaciones sureñas de la Patagonia y la región de Magallanes, como insiste Joaquín Bascopé.

Pese a la plasticidad organizativa para la guerra, la gestión de la territorialidad y la eficiencia del lazo social mapuche, aquello que Dillehay llama el
Estado nunca habría logrado establecer un dominio centralizado, ni evitar la captación de agentes por parte de los españoles como los ambiguos "indios amigos", muchos de los cuales eran los mismos grandes hombres mapuches, y con cuya mediación se suscribieron tratados y se entablaron relaciones de todo tipo con los aparatos eclesiásticos que incluyeron la escolarización de los hijos de los caciques principales. Este matiz es central, y en parte colisiona con la hipótesis más general de la autonomía, ya que el fenómeno colonial estuvo en el corazón de la política mapuche, permitiendo entender aquello que hemos llamado "jefaturas de nuevo tipo" (Vezub 2009), una clase de liderazgos flexibles que apuntaron a la supervivencia y la negociación con la autoridad por lo menos desde mediados del siglo XVIII, impulsando alianzas que se manifestaron en la política de bautismos y nombres españoles, el desarrollo del comercio ganadero con los hacendados hispano-criollos, la adopción del alfabeto español, la jerarquización militarizada de las relaciones de parentesco dentro de la estructura defensiva de las fronteras, y el "Negocio Pacífico de Indios" en las pampas (Ratto 2003), que trasladó una parte significativa de los beneficios al lado occidental de los Andes, y que en Chile tuvo su correlato más modesto como política de "agasajos". Estos mecanismos de negociación redujeron territorialidades a la vez que crearon "dependientes orgullosos" entre los jefes mapuches que recibían las raciones, que las justificaban como el tributo que era pagado por los extranjeros o huincas por el permiso para hacer uso de los campos (Foerster y Vezub 2011). A ambos lados de la cordillera, si bien los reductos políticos y territoriales como el País de las Manzanas del Neuquén mantuvieron su vigor, nuevos trabajos y documentaciones desdibujan la imagen de una Araucanía indómita desde el fin de la guerra de Arauco hasta la caída del fuerte de Villarrica durante la Pacificación, o hasta las campañas del general Roca de las décadas de 1870 y 1880.

Se ha escrito y dicho que los mapuches contemporáneos están más cercanos de las posturas de los vascos e irlandeses que de otras etnias americanas, o "pueblos originarios", por su tipo de reivindicación nacional. Y ello es compatible con la difusión de los particularismos en un contexto de neoliberalismo, globalización y debilitamiento de las estructuras jurídicas y simbólicas de los estados nacionales. Aquí es donde se dificulta la idealización 
del araucano/mapuche afecto a la naturaleza y la tierra, la cosmovisión ecológica y las prácticas ancestrales por fuera de su historicidad. En esta visión los mapuches se presentan uniformemente resistentes (o resilientes) al Estado moderno, planteándose una dicotomía de aristas rígidas y sin permeabilidad cultural. De acuerdo con mi crítica, el principal problema del texto es que el análisis del proceso histórico tiene un hiato entre los siglos XVI-XVII y la actualidad, pasando muy rápidamente por los siglos XVIII y XIX, sin problematizar la historia mapuche del siglo XX, todas centurias claves para el desarrollo de la relación colonial, primero con España y después con las repúblicas emergentes. Es allí donde los mecanismos de penetración del Estado, la producción de la soberanía y las lógicas compartidas se despliegan con toda intensidad. Categorías como "resiliencia" y "gobernanza", que se podría consultar al autor para que amplíe en su respuesta cómo funcionan en este extendido caso histórico, resultan extrapoladas al retrotraerlas del presente neoliberal al pasado en los bordes del Imperio Español, sintomáticas de su anacronismo cuando se recurre a la cita del primer ministro italiano Prodi acerca del autogobierno, o se introduce el ejemplo de la Comunidad Europea (qué decir del ejemplo de la gobernanza después del Brexit). Las mismas resultarían difícilmente honrosas para los guerreros que se consideraban parte de una casta superior de vencedores, si es que se retorna a la propuesta más interesante de atender cuáles eran los conceptos que producían sentido para los actores de entonces.

En contraste con su fortaleza para describir el sistema de gobierno mapuche de los siglos tempranos, la principal debilidad del texto es la pintura de un icono de imaginación étnica, la idealización de mapuches sin someter que habrían mantenido una cosmovisión trascendente y sin contradicciones desde la guerra de Arauco hasta el presente, saltándose los siglos XVIII y XIX, e incluso el XX, cuya historia permite discutir cómo esa imagen de soberanía e independencia, o el oxímoron de un "estado sin Estado" incontaminado con los criterios de Occidente, construido sobre la base de consensos pluralistas, libertario o no jerárquico y a la vez nacionalista, enraizado en la naturaleza sagrada de la relación con la tierra, se produce retrospectivamente como efecto de la militancia, los discursos globales y la historiografía. Y conforme veo las ambivalencias del proceso histórico, esto se ha gestado no solamente desde posiciones étnico-autonomistas, sino también desde el mito de la raza como basamento de la nacionalidad chilena. Según el devenir que plantea el texto no habría pacto, alianza, ni deseo de Estado moderno entre los mapuches que negociaron y resistieron tanto con el colonialismo europeo como a partir de las revoluciones de independencia que produjeron ambas repúblicas sudamericanas. Cuál es el grado histórico de exterioridad mapuche respecto del Estado y sus prácticas es la pregunta que queda por responder.

\section{Referencias Citadas}

Abrams, P. 1998. Notes on the Difficulty of Studying the State. Journal of Historical Sociology 1(1):58-89.

Bechis, M. 2008. Piezas de Etnohistoria del Sur Sudamericano. Consejo Superior de Investigaciones Científicas, Madrid.

Bello, Á. 2011. Nampülkafe. El Viaje de los Mapuches de la Araucanía a las Pampas Argentinas. Territorio, Política y Cultura en los Siglos XIX y XX. Universidad Católica de Temuco, Temuco.

Boccara, G. 1998. Guerre et Ethnogenèse Mapuche dans le Chili Colonial. L'invention du soi. L'Harmattan, Paris.

Cox, G. 1863. Viaje en las Rejiones Septentrionales de la Patagonia, 1862-1863. Imprenta Nacional, Santiago.

Deleuze, G. y F. Guattari 1988 [1980]. Mil Mesetas, Capitalismo y Esquizofrenia. Traducido por José Pérez Vázquez. Pre-textos, Valencia.

Dillehay, T.D. 2011 [2007]. Monumentos, Imperios y Resistencia en los Andes. El Sistema de Gobierno Mapuche y las Narrativas Rituales. Traducido por Marcelo González Gálvez. Universidad Católica del Norte, San Pedro de Atacama.
Foerster, R. y J.E. Vezub 2011. Malón, ración y nación en las pampas: el factor Juan Manuel de Rosas (1820-1880). Historia 44:259-286.

González, A.R. 1979. Las exequias de Painé Güor. El sutte entre los araucanos de la llanura. Relaciones de la Sociedad de Antropología XIII:137-161.

Hämäläinen, P. 2011. El Imperio Comanche. Traducido por Ricardo García Pérez. Península, Barcelona.

Levaggi, A. 2000. Paz en la Frontera. Historia de las Relaciones Diplomáticas con las Comunidades Indígenas en la Argentina (Siglos XVI-XIX). Universidad del Museo Social Argentino, Buenos Aires.

Menard, A. 2010. Canibalismo, nobilismo y heterogeneidad: comentario al libro Los vencedores de Guillaume Boccara. Revista Chilena de Antropología 21:149-178.

Pavez Ojeda, J. 2008. Las cartas del Wallmapu. En Cartas Mapuche Siglo XIX, compilado por J. Pavez Ojeda, pp. 9-114. Ocho Libros/CoLibris, Santiago. 
Ratto, S. 2003.Una experiencia fronteriza exitosa: el Negocio Pacífico de Indios en la Provincia de Buenos Aires (1829-1852). Revista de Indias 63:191-222.

Sloterdijk, P. 2006. Esferas III: Espumas. Siruela, Barcelona.
Vezub, J.E. 2009. Valentín Saygüeque y la "Gobernación Indígena de las Manzanas”. Poder y Etnicidad en la Patagonia Septentrional (1860-1881). Prometeo Libros, Buenos Aires. 
